\title{
Teorizações dos Docentes sobre a Avaliação em Artes Plásticas
}

\author{
Suzana Maria Ortiz dos Santos
}

\section{Resumo}

propósito deste texto é apresentar em síntese a tese "Teorizações dos docentes sobre a avaliação em Artes Plásticas", que busca indagar e compreender o pensamento do professor de Artes Plásticas na avaliação dos alunos da $5^{\text {a }}$ série do Ensino Fundamental no Brasil. Este estudo enquadra-se em um enfoque qualitativo não experimental de tipo exploratório. Através das entrevistas com os professores, a declaração do docente considerada "uma ação mediada pela palavra", buscou-se as teorias implícitas a fim de tornarem-se explícitos os marcos de referência do professor de Artes Plásticas e compre-

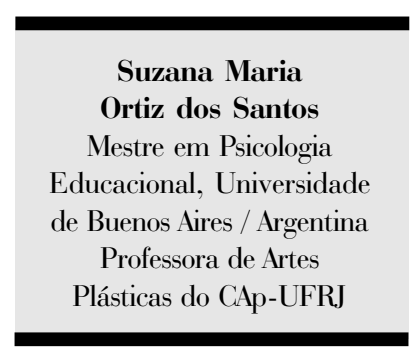

escola a atividade de avaliar nas Artes Plásticas consiste na atribuição de um juízo de valor a uma realidade observada; no processo de avaliação nas Artes Plásticas busca-se uma ação reflexiva, "o avaliar" dentro da proposta da avaliação diagnóstica e formativa; o conhecimento do professor pode ser considerado um conhecimento leigo e também como teorias pedagógicas pessoais (teorias implícitas), estas nem sempre percebidas pelos professores, porém fazem parte de um papel importante na organização do conhecimento do professor.

Palavras-chave: pensamenender como ele percebe, pensa, teoriza e compreende sobre a avaliação nas Artes Plásticas. $\bigcirc$ interesse do investigador foi desafiar um campo pouco revisto, que é o campo da Psicologia, da Arte e da Didática, buscando um ponto onde se encontram o psicológico, o didático e o artístico. As escolas públicas municipais do Rio de Janeiro foram o lugar de trabalho. Das declarações obtidas nesta investigação, chega-se a determinados resultados: os dados trazem evidências de que na to do professor. Avaliação em Artes. Teorias implícitas. Compreender. Juízo de valor. Ação reflexiva. Conhecimento leigo. Psicologia. Arte. Didática.

\section{Introdução}

Este artigo tem como base a dissertação de Mestrado "Teorizações dos docentes sobre a avaliação em Artes Plásticas" vinculada à área de especialidade "Processos Psico-Educativos na Interface Saú- 
de e Educação" e com um projeto maior chamado: "Avaliação: Esquemas Interpretativos e Aprendizagens Docentes" (Psicologia UBA / Argentina).

Acreditando e apoiando esta dissertação as professoras Thereza Penna Firme, orientadora no Brasil, e a professora Gisele Gama Andrade, co-orientadora, suas orientações profissionais e de amizade foram decisivas ao estudo.

Neste projeto o interesse está em indagar os esquemas interpretativos dos docentes nos processos de avaliação dos alunos e identificar as necessidades de aprendizagem que os próprios docentes têm a respeito.

A partir da vinculação com este projeto maior houve o interesse de indagar as teorizações dos docentes sobre a avaliação em Artes Plásticas, docentes estes que trabalham diretamente com alunos de $5^{\circ}$ série do Ensino Fundamental da Secretaria Municipal de Educação (Rio de Janeiro). Outro interesse foi indagar e compreender o pensamento do docente de Artes Plásticas. Considerando-se que nas escolas públicas o ensino das Artes Plásticas e a sua avaliação são iniciados formalmente na $5^{\circ}$ série e que neste período da préadolescência a compreensão dos alunos passa pelo caminho da experiência e das diferentes fases, podendo evoluir da fase operatória-concreta em transição ao nível do pensamento formal e podendo compreender o significado das formas, das linhas e das cores, surgindo uma inquietude de ordem estética e onde o trabalho de avaliação do aluno pode ser realizado de maneira mais direta, surge neste campo o interesse maior do pesquisador.
A educação da arte é um campo de prática educativa que não tem tradição investigadora científica igual ou similar comparável à da psicologia, da sociologia ou qualquer das ciências "duras".

No estudo recorrido sobre a temática da "avaliação de aprendizagem" encontrou-se que é um dos temas mais conflitivos da Pedagogia, onde se enfrentam posturas de maneira consciente e inconsciente. $\bigcirc$ desconhecimento da natureza desta avaliação, as motivações, as atitudes, os sentimentos ocultos detrás das apreciações dos professores com relação ao sucesso alcançado pelos seus alunos seguem hoje em dia. Neste sentido são poucos os trabalhos que se ocupam das percepções e das teorizações dos participantes no processo de avaliação.

$\bigcirc$ interesse do pesquisador foi desafiar um campo pouco revisado, que é o campo da Psicologia, da Didática e da Arte, buscando um ponto de intersecção do psicológico, do didático e do artístico.

pesquisador utiliza o termo "teorizações do professor" consideradas como elaborações do professor que fazem parte do repertório pessoal-profissional de seu conhecimento, que guiam e dão sentido às ações do professor.

Entende-se também pelo termo "pensamento do docente" um marco de referência integrado por um cúmulo de teorias implícitas, representações, imagens, suposições, noções, idéias, intenções, projetos, supostos, hipóteses, crenças, atitudes, interesses e valores suscetíveis de influir na seleção de critérios para avaliar aos estudantes e para tomar decisões sobre que, quando e como 
planejar, atuar e avaliar os processos de ensino e aprendizagem (COLL; MIRAS, 1993 apud MONROY, 2000).

A tomada de posição que se faz neste trabalho está mais próxima da busca de estreitas relações entre as teorias implícitas (MARRERO, 1993 apud RODRIGO; RODRÍGUEZ PÉRES; MARRERO, 1993, grifo nosso) e as teorias pessoais dos docentes (FELDMAN, 1995, grifo nosso). Não se negam as outras características ou outros termos existentes, porém prefere-se considerá-los como dimensões de uma estrutura complexa.

Por que os estudos das teorias implícitas nas teorizações dos docentes? As teorias implícitas tornam possível a busca das teorizações que os docentes têm com relação à planificação do processo de ensino e aprendizagem, os critérios de avaliação dos trabaIhos dos alunos e os juízos mediante os quais elegem as atividades que implementam para ajudar à construção de conhecimentos.

O estudo das teorias explícitas e implícitas dos docentes torna possível compreender as teorizações que eles têm sobre sua função docente.

\section{O Problema - O Objetivo}

O propósito da presente pesquisa foi indagar e compreender o pensamento do docente de Artes Plásticas na avaliação dos alunos em um processo de aprendizagem escolar.

Houve o interesse de documentar a presença simultânea de critérios psicológicos e pedagógicos com suas especificidades conceituais, metodológicas e técnicas sobre a avaliação dos alunos em Artes Plásticas. A pesquisa centrou-se na reconstru- ção de conhecimentos explícitos e implícitos dos docentes acerca das teorizações referidas à avaliação dos alunos.

Propôs-se sistematizar as teorizações dos docentes de Artes Plásticas para que se pudesse converter em explícitos e visíveis os marcos de referência por meio dos quais cada docente percebe e processa a informação.

\section{Primeiros Questionamentos}

Quais são as idéias e teorias que se impõem nas declarações dos docentes de Artes Plásticas acerca da avaliação?

As idéias que compõem as teorizações dos docentes em Artes Plásticas acerca da avaliação são comuns a todos os docentes ou diferem segundo suas concepções próprias, suas interpretações próprias, suas experiências e sua formação acadêmica?

De que modo as teorias implícitas dos docentes de Artes Plásticas acerca do processo de avaliação podem vincular-se com a maneira em que se avalia o aluno?

\section{Dados Específicos da Pesquisa}

Especificação do lugar de trabalho: oito escolas públicas municipais do Ensino Fundamental do Rio de Janeiro, que estão localizadas em bairros de classe média, com uma clientela de alunos de $5^{\circ}$ série do Ensino Fundamental, classe de baixa renda, que vivem em bairros humildes e em favelas ao redor dos bairros de classe média na cidade do Rio de Janeiro.

Entrevistados dez docentes de Artes Plásticas, brasileiros, que pertencem à classe média em geral, com mais de dez anos de serviço, atuantes na profissão. 


\section{Perspectivas Teóricas}

$\mathrm{Na}$ articulação dos resultados sistematizados das declarações dos docentes e nos referentes teóricos que se utilizou na interpretação dos dados surgem autores como Bruner (1991), Pozo (1989, 1998, 1999), Feldman (1995, 1999), Rodrigo, Rodríguez Péres e Marrero (1993), Perrenoud (1996, 1999), Bertoni e outros (1999, 2000), Elichiry (2000a, 2000b) mais especificamente em Artes Plásticas os autores como Dewey (1949, 1980, 1998), Eisner (1995, 1998) e no Brasil Ostrower (1983, 1991, 1998), Barbosa (1996, 2000, 2000 a, 2001 b) e Duarte Jr. (1995).

Os estudos sobre a "psicologia popular", "psicologia intuitiva" ou simplesmente chamado "sentido comum" se encontram entre os referentes teóricos. Bruner (1991) considera que é um sistema mediante o qual a gente organiza sua experiência, seu conhecimento e suas transações relativos ao mundo social. Uma "psicologia popular" não somente deve estar baseada no que as pessoas fazem "mas também no que dizem que fazem, e no que dizem que os levou a fazer o que fizeram." (BRUNER, 1991). Podem-se compreender as ações do professor como ações situadas, ou seja, o que o docente faz adquire sentido no marco da situação em que se produz e das intenções que "dizem" que as guiam. Ou seja, como a "psicologia popular" trata de agentes humanos que fazem coisas baseando-se em suas crenças e seus desejos, esforçam-se por alcançar metas e encontram obstáculos que superam ou não, tudo ocorrendo em um período prolongado de tempo.

Pozo (1989, 1998, 1999) também considera que todos nós possuímos idéias ou teorias informais sobretudo naqueles domínios do "mesocosmos", traçados pelas co- ordenadas espaço-temporais do aqui e do agora, que afetam a nossa vida cotidiana. Há um conhecimento informal sobre o mundo social e histórico, seja uma matemática intuitiva, um conhecimento intuitivo ou implícito no uso das tecnologias ou na produção artística, uma psicologia intuitiva que todos, professores e alunos, utilizam para dar sentido a sua prática cotidiana nas aulas e que é muito resistente à mudança [...]. O autor fala também das definições do conceito de "aprendizagem" e sobre o "bom aprender" e o que se entenderá por "avaliação" no seu sentido especificamente educativo.

Feldman (1995) e Marrero (RODRIGO; RODRÍGUEZ PÉRES; MARRERO, 1993) concordam em que não é possível interpretar o valor das teorias pessoais dos docentes sem relacioná-las com suas condições de trabalho e de ensino. [...] as pessoas conhecem e aprendem em atuações com outras pessoas e em determinadas condições de existência. Consideram que o conhecimento do docente é pessoal, mas não individual, pois interagem com uma realidade "culturalizada" pedagogicamente e combina, em diferente proporção, aspectos tácitos e explícitos. Marrero (RODRIGO; RODRÍGUEZ PÉRES; MARRERO, 1993), considera que as teorias implícitas são teorias pedagógicas pessoais reconstruídas sobre a base de conhecimentos pedagógicos historicamente elaborados e transmitidos através da formação e na prática pedagógica. Portanto, as teorias implícitas são uma síntese de conhecimentos culturais e experiências pessoais. E se apóiam em uma teoria da mente de caráter socioconstrutivista para poder explicar como os professores dão sentido ao trabalho dos professores. 
Perrenoud (1996, 1999) foi relevante aos estudos questionando a complexidade do problema sobre a avaliação educativa, que se deve à diversidade de duas lógicas, uma tradicional e outra emergente, e que a avaliação está nas contradições do sistema educativo, constantemente na articulação da seleção e da formação, do reconhecimento e da negação de desigualdades. Outra autora, Bertoni (BERTONI; POGGI; TEOBALDO, 1999; BERTONI; TORRES; CELMAN, 2000) também considera que as questões referentes às práticas de avaliação e os saberes dos docentes como a construção de significados novos para velhas práticas devem ser revistas. Em relação às práticas e processos de avaliação, Elichiry (2000a, 2000b) reflexiona sobre os processos de avaliação do sujeito educativo, seja o aluno seja o professor, que envolvem processos psicológicos referidos ao desenvolvimento de valores, crenças, noções de mundo e noções de si mesmo. Com a autora surge também o questionamento sobre os valores implícitos com respeito à responsabilidade social e moral que cabe aos avaliadores, um processo de construção que inclui a interação de fatores políticos, culturais, axiológicos e representações sociais.

Especificamente em Artes Plásticas, John Dewey $(1949,1980,1998)$ foi retomado devido a sua influência aos educadores de todo o mundo com sua tese fundamental de que a arte é "uma experiência". $\bigcirc$ conceito de "experiência" é aplicado para designar qualquer dos processos conscientes de nossa vida e que em cada momento da existência se vive uma experiência. A idéia de que a "experiência verdadeira" é uma organização do novo e do velho, de maneira que os valores e significados anterio- res adquiram nova vida no estado presente e se desenvolvam como uma experiência nova. Outra idéia relevante foi de que a experiência estética não se vive em vista de um final, mas que todas as fases do processo têm seu valor no resultado final.

As idéias de Elliot Eisner (1995, 1998) abordando as questões sobre a avaliação em Artes Plásticas e a questão da eficácia, estimulando a considerar a pesquisa de idéias próprias das artes e a avaliação própria como vias para descrever relações e valorizar seus caminhos para melhorar a prática educativa. Especificamente no Brasil, os estudos de Ana Mae Barbosa (1996, 2000, 2001a, 2001 b) sobre a "Proposta Triangular" são baseados nos projetos de Eisner (1995, 1998) como articulador, sob o nome de DBAE (Discipline-Based Art Educacion). Esta proposta artística cobra um reconhecimento similar ao de outras disciplinas do currículo, e organiza seus conteúdos de acordo com quatro disciplinas: a estética, a história, a crítica e a produção artística. Hoje em dia, está intervindo qualitativamente no processo e melhoria do ensino da arte no Brasil e tem por base um trabalho pedagógico integrador de três facetas do conhecimento em arte: o fazer artístico, a análise de obras artísticas e a história da arte. Para o momento em que se vive, responde ao valor fundamental a ser buscado na educação no Brasil: a leitura e a alfabetização.

Ainda referentes à avaliação em Artes, as idéias de Duarte Jr. (1995) quanto ao processo de análise dos trabalhos elaborados pelos alunos, devendo ser relativo aos termos conseguidos e dos sentimentos e idéias que ocorreram ao longo do processo vivido. As idéias de Fayga Ostrower (1983, 1991, 
1998) podendo-se relacionar a temática da criatividade e seus processos de criação com o pensamento do docente de Artes Plásticas, este diretamente inserido em um contexto escolar e necessitando refletir e teorizar sua prática com o aluno.

A partir destes delineamentos que os estudos foram dirigidos, desafiando um campo pouco revisto, que é o campo da Psicologia, da Didática e da Arte e buscando um ponto de intersecção do psicológico, do didático e do artístico.

\section{Metodologia}

Nesta pesquisa foi utilizado um enfoque qualitativo com um desenho não experimental, para estudo de tipo exploratório. Reconhecendo-se ao longo da pesquisa qualitativa a necessidade da organização dos dados em uma forma mais quantitativa, ou seja, a necessidade de "quantificar o qualitativo", assim foi sendo reestruturada a forma metodológica inicial.
"Reconhece-se também a pluralidade de vias para aceder à realidade social, porém não se trata de afirmar um paradigma sobre outro, mas de buscar compatibilidades entre eles" (D'ANCONA, 1998, p. 47). "É tempo de deixar de construir muros entre métodos e começar a construir pontes" (REICHARDT; COOK, 1979 apud D'ANCONA, 1998, p. 47), exemplifica esta predisposição à complementaridade entre paradigmas, e não a sua oposição.

Foi utilizado um enfoque metodológico combinado e alternativo: prova piloto, notas de campo, entrevistas inicialmente abertas e depois semi-estruturadas, estudos de casos, coleta de produções (trabalhos de alunos) e análise de documentos oficiais.

As perguntas foram organizadas em categorias. Uma vez finalizadas as entrevistas as categorias foram novamente reagrupadas em outros três blocos de categorias e em seguida sub-divididas em sub-categorias.

\section{Tabela de Categorias}

\begin{tabular}{|c|c|}
\hline CATEGORIAS & SUB-CATEGORIAS \\
\hline $\begin{array}{l}\text { I - O QUE É? } \\
\text { APOIO CONCEITUAL } \\
\text { OBJETO CONCEPÇÃO }\end{array}$ & $\begin{array}{ll}\text { I - } 1 & \text { APOIO CONCEITUAL } \\
\text { I - } 2 & \text { CONCEPÇÃO }\end{array}$ \\
\hline $\begin{array}{l}\text { II - PLANEJAMENTO } \\
\text { E MÉTODO }\end{array}$ & $\begin{array}{l}\|-1 \text { POR QUÊ? / INTENÇÃO } \\
\|-2 \text { CRITÉRIOS/ PERCEPÇÃO/ } \\
\text { E ATRIBUIÇÃO DE NOTAS } \\
\|-3 \text { MODO / COMO } \\
\|-4 \text { CONCEITO APRENDIZAGEM EM ARTES } \\
\|-5 \text { ENSINO / DIDÁTICA } \\
\|-6 \text { CONSEQUÊNCIAS / EFEITOS/ PARA QUÊ? } \\
\|-7 \text { O QUE SE AVALIA? / FOCO } \\
\|-8 \text { UTILIZAÇÃO / COMUNICAÇÃO }\end{array}$ \\
\hline $\begin{array}{l}\text { III - DOCENTE E ALUNO / } \\
\text { SUJEITOS EDUCATIVOS }\end{array}$ & III - 1 SUJEITOS EDUCATIVOS \\
\hline
\end{tabular}




\section{Conclusões}

Inicialmente é necessário esclarecer que se está frente a um processo de avaliação do aluno, uma prática profissional nada simples, com várias operações implicadas, pois consiste em um processo de aquisição, elaboração de informação, expressão de um juízo de valor e comunicação a partir da informação coletada.

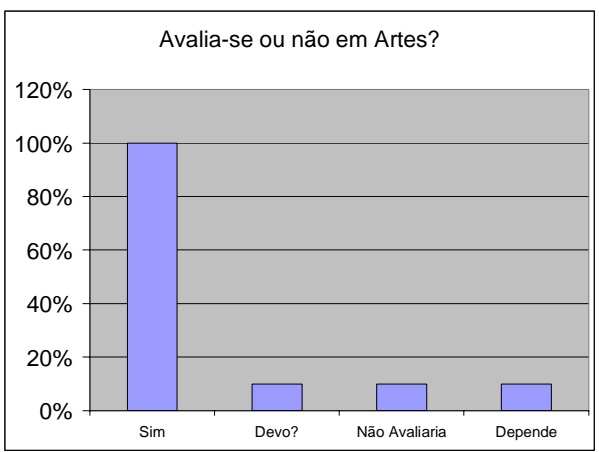

Determinadas conclusões são apresentadas a seguir:

O conceito de avaliação tem uma amplitude variável de significados possíveis e os termos mais utilizados pelos docentes para definir "avaliar" são: valorizar, compreender e estimular para crescer. De toda forma, surgem termos ambíguos e opostos como: valorizar, compreender, estimular para crescer, julgar, dar crédito/dar nota, verificar, medir e fiscalizar. Expressa uma coisa e seu contrário: o preciso e o aproximado, o quantitativo e o qualitativo.

Não foi percebido um questionamento da profundidade dos termos para definir "avaliar" e seus significados com relação às problemáticas de suas implicações sociais, econômicas, políticas, institucionais e pedagógicas explicitamente nos docentes, considerando-se que a maioria dos professores não se baseia em qualquer teoria ou enfoque entre os diversos paradigmas históricos ou concepções de ensino. Nem sempre os docentes sabem o que realmente significam os termos e suas diferenças conceituais. Em uma análise mais detalhada, os professores parecem ter como marcas e rasgos em suas teorizações, influências sofridas pelas duas teorias ou correntes pedagógicas mais percebidas: a ativa e a construtiva. A existência da teoria nem sempre é percebida pelos professores e muitas vezes adquire uma presença silenciosa. Nem todo conhecimento do professor pode ser considerado idiossincrásico e individual.

conhecimento do professor pode ser considerado um conhecimento leigo, não somente científico, na medida em que se constrói de maneira espontânea, a partir de atividades diárias de ensino e de interações educativas em sala, busca resolver problemas práticos e imediatos e eficácia a curto prazo. Por exemplo, uma declaração de docente quando perguntado: "Como você percebe o aluno como um sujeito-educativo que aprende e ao mesmo tempo nos ensina?" declarou: "Todo o tempo em que você está com o aluno, está aprendendo algo. É ao longo das aulas, ao longo da convivência com o aluno".

Os resultados nos levam à confirmação com relação aos estudos das teorias implícitas do professorado de Marrero (RODRIGO; RODRÍGUEZ PÉRES; MARRERO, 1993). O docente durante sua formação possui significados explícitos e outros que são resultados de experiências, e neste caso as pautas de avaliação também: seus conteúdos, suas destrezas, seus hábitos, suas orientações metodológicas e outras mais, que vão depender diretamente de qual seja 
sua concepção sobre a avaliação. Entretanto muitas de suas teorizações permanecem implícitas e nem sempre resulta simples expressá-las de forma coerente. De acordo com o enfoque de Marrero, o enfoque de De la Cruz (1999) e as declarações dos docentes, se pode considerar que os processos de pensamento dos docentes e suas ações mantêm uma relação recíproca, onde estas ações se originam nos processos de pensamento que por sua vez são afetados pelas próprias ações.

No processo de avaliação dos alunos de Artes Plásticas se conclui que o docente busca cada vez mais "o avaliar" dentro da proposta da avaliação formativa, um fim da separação clássica entre didática e avaliação, mesmo que ele não declare exatamente que "teoriza" explicitamente sobre o conceito de avaliação formativa. Segundo Penna Firme (1994) "é preciso entender o processo natural das nossas crianças, dos nossos jovens, de nossos educadores e de nossas instituições e trabalhar na direção da compreensão e da autenticidade. Falo, portanto, de uma avaliação que vai respondendo, na medida em que vai esculpindo e trabalhando seu objeto de atenção. $\bigcirc$ avaliador é, em essência, um educador, seu sucesso deve ser aquilatado pelo que se aprende dele [...]. Por outro lado, e reciprocamente, o educador deve ser um avaliador, na medida em que põe toda a sua sensibilidade e a plenitude de sua inteligência na compreensão e no impulsionamento de sua missão".

De acordo com as declarações mais citadas, os professores indicam como aprende o aluno em Artes Plásticas: "depende da experiência do aluno" (50\%), "não explica bem como aprende o aluno em Artes
Plásticas" (60\%) e "não sabe bem" (10\%). A maioria ainda pensa que a mente do aluno permanece uma caixa negra, ou seja, o que se passa não é direta e totalmente observável. "Sem a compreensão global de como funciona a mente humana resulta difícil compreender porque às vezes aprender resulta tão difícil, em troca, resulta tão fácil e favorável que aprendamos inclusive o que não queremos aprender" (POZO, 1999, p. 1 18). Por exemplo, uma declaração de docente quando perguntado "Como aprende o aluno em Artes Plásticas? E falemos em mau aluno e em bom aluno [...]" declarou "Nem mau aluno nem bom aluno, não é isso. É uma questão de criatividade, não sei explicar bem porque um aluno faz algo melhor que outro, penso que é uma questão da mente de cada um".

A avaliação tem diversos efeitos sobre a aprendizagem, entre eles o de prover informação ao professor e ao aluno sobre os progressos e os obstáculos que se encontram no processo de sua aprendizagem, como os possíveis erros que o aluno e o professor devem superar. Outro efeito mais é o de incentivar a motivação do aluno por aprender. Por exemplo, uma declaração de docente quando perguntado sobre os diversos efeitos da avaliação sobre a aprendizagem [...] nas perguntas " $\bigcirc$ que se avalia em Artes Plásticas? E quais são os aspectos que você prioriza ao avaliar o aluno em Artes Plásticas?" declarou "O aluno que pelo menos tenta fazer alguma coisa, mesmo que não alcance ou não consiga, não pode ser considerado mau aluno. Você tem que aproveitar o que ele faz". $\bigcirc$ professor nesta questão dos efeitos e benefícios da avaliação nas Artes Plásticas, nesta etapa da pré-adolescência, considera a auto-estima do aluno como um fator de relevância no processo de ensino e apren- 
dizagem; e as práticas da avaliação têm uma influencia decisiva nos alunos e nos professores, onde as relações sociais dentro de sala e no entorno social os resultados transcendem em valorações dos sujeitos, como pontos de referência para a auto-estima.

Outra visão sobre os efeitos e benefícios da avaliação é a de que ela desempenha diversas funções, mas sua utilidade mais chamativa não é necessariamente a pedagógica, e sim se avalia pela função social que com seu uso se cumpre: "como uma missão historicamente destinada à escola e aos professores em concreto e se realiza em um contexto de valores sociais, por umas pessoas e com uns instrumentos que não são neutros" (GIMENO SACRISTÁN, 1992, p. 364). Por exemplo, alguns docentes quando perguntados "Para quem se avalia em Artes Plásticas?" declararam "A Instituição avalia de forma quantitativa. Para os alunos seria uma avaliação qualitativa, porque assim os alunos teriam de avaliar, de tentar [...]. Ao professor seria também qualitativa, porque o professor melhora, modifica [...]. Para os pais, eles têm uma visão como a da própria Instituição, de aprovação ou reprovação, está bem ou está mal, não têm a preocupação do crescimento individual"; "Essa avaliação em quanto à medição, se avalia para a Instituição. Não sei se para os pais [...]. Para mim, não. Dar a nota, não. Para o aluno porque faz parte do processo".

A maioria dos professores indica como critérios principais de avaliação nas Artes Plásticas, segundo a visão do pesquisador, os aspectos que fazem parte do Bloco I (aluno), que dependem da própria atuação do aluno (sua conduta); em sua menor intensidade os aspectos que fazem parte do Bloco
II (artes/conceitos), que dependem da informação dos conhecimentos artísticos e indicam em sua menor ênfase os aspectos que fazem parte do Bloco III (alunos/artes), que dependem da combinação aluno e informação dos conhecimentos artísticos adquiridos.

A maioria dos professores indica como critérios de êxito em Artes Plásticas: o aluno participativo, interessado (60\%) e se o trabalho do aluno está dentro da proposta e vai mais além do que o professor pediu (50\%). A maioria dos professores indica que NÃO existe o fracasso (70\%) e a minoria que SIM existe o fracasso (30\%). Os critérios mais citados são: que o aluno faça o trabalho por fazer, que o aluno não faça nada e não produza e que seu fracasso seja o fracasso do professor. Apesar destes dados acima, surgem outros onde a maioria dos professores (80\%) diz que SIM existe o mau aluno e a minoria (20\%) que não existe o mau aluno. Os professores consideram como mau aluno: o aluno preguiçoso e que não quer nada (40\%); como bom aluno: a quem trabalha (40\%), quem sempre tenta, não se desanima, tem boa vontade e é interessado (30\%). Ser capaz em Artes Plásticas, dentre os critérios mais citados: 0 aluno que percebe mais, o aluno que se expressa no trabalho, o aluno que tem habilidades, o aluno que executa as tarefas e o aluno que tem novas formas de criar/criatividade (20\%). A escola elabora as hierarquias de excelência, em especial as que decidem o fracasso ou êxito escolares e suas conseqüências, e o docente neste sistema complexo elabora seus próprios procedimentos e normas das hierarquias de excelência, onde se define 0 mau aluno e o bom aluno, e se fabrica uma nova realidade, com uma significação própria das desigualdades reais. É uma 
construção intelectual, cultural e social, e também uma verdadeira fabricação, segundo procedimentos e juízos relativamente estáveis, em parte codificados pela organização escolar e em parte inventados por cada docente, sendo em parte uma fabricação artesanal (PERRENOUD, 1996).

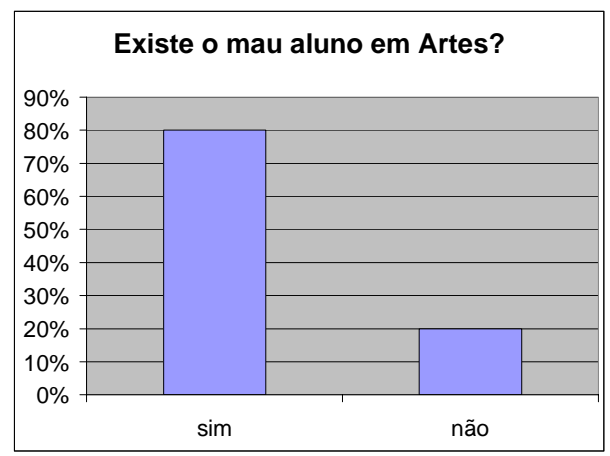

As declarações dos docentes mostram que existe um contrato didático entre o professor e seus alunos, e também entre o professor e a Instituição, um acordo implícito ou explícito, pelo qual se exige que o professor não ponha sistematicamente os alunos em situação de fracasso e também não expulse ninguém durante o curso, sob pena de desorganizar a gestão de fluxo de alunos da escola pública.

Os resultados também trazem evidências de que a maioria dos professores de $\mathrm{Ar}$ tes Plásticas (60\%) SIM compara o trabaIho do aluno com critérios estéticos e que a minoria (40\%) NÃO compara o trabalho com critérios estéticos, sendo que a maioria (80\%) NÃO o compara com critérios estéticos de "boa ou má arte". Goodman (1976 apud GARDNER, 1993, 117) afirma que é extremamente difícil encontrar pautas para julgar este aspecto sobre a avaliação dos trabalhos dos alunos com critérios estéticos. Um desenho funciona como símbolo estético na medida em que explora as propriedades expressivas e plenas do meio gráfico. De toda forma, mesmo considerando estas definições um ponto de partida útil, Gardner (1993, p. 162) considera que "qualquer avaliação individual destas qualidades seguirá sendo altamente subjetiva". No processo de avaliação, os progressos dos alunos, seus estancamentos ou retrocessos devem ser verificados com relação ao seu próprio ponto de partida e é qualitativamente, em termos individuais que se deve proceder a essa avaliação. De toda forma, isso não quer dizer que seja irrelevante auxiliar o aluno a desenvolver uma consciência estética. $\bigcirc$ principal propósito da educação estética, para todos, é principalmente a formação do apreciador da arte (BARBOSA, 2000).

Com relação à categoria "Docente e Aluno: Sujeitos Educativos", mais especificamente a "Sujeitos Educativos", os professores como avaliadores de um processo educativo percebem o aluno como um sujeito educativo que aprende e ao mesmo tempo nos ensina, segundo algumas declarações a seguir indicadas: "nós aprendemos com o aluno, aprendo muito com eles, como aprendo!, se ainda estou na escola municipal é porque aprendo muito com eles, penso que a pessoa sempre aprende, penso que isso traz muito benefício, todo o tempo em que você está com o aluno está aprendendo alguma coisa e é ao longo da aula, com a convivência do aluno, penso que há uma troca, todo o tempo, com as crianças pequenas também, hoje sou uma professora melhor que antes devido a essa troca, o aluno como um sujeito da ação e os educadores também, esse sujeito educativo é o mais precioso que nós 
temos na educação, e de experiência de vida também e de sua experiência, mesmo em momentos em que o aluno não imagina nos ensina, tudo isso é percebido durante o processo [...]". Toda relação que seja realmente vivenciada e participativa é educativa para os que dela compartem (DEWEY, 1980).

De acordo com as declarações os docentes reconhecem que aprendem na escola e que aprendem com os alunos, porém nesse processo se considera que uma série de saberes prévios está em jogo para a contextualização nas aprendizagens presentes, considerando que o conhecimento do docente também é o resultado de sua própria ação, sua experiência pessoal, sua reflexão e que suas teorizações repercutem em suas práticas. $\bigcirc$ docente não é somente o sujeito "cognoscente", pois a aprendizagem está comprometida com a subjetividade, mais que isso, sujeito epistêmico, sujeito afetivo, sujeito social e sujeito cotidiano (ELICHIRY, 2000).

Os resultados da pesquisa trazem evidências de que na escola a "atividade de avaliar" em Artes Plásticas também consiste na atribuição de um juízo de valor a uma realidade observada, utilizando cada vez mais uma ação mais reflexiva. Por exemplo, alguns docentes quando perguntados quanto aos trabalhos dos alunos "São estes os trabalhos mais próximos de um sucesso em Artes?" declararam "É importante lembrar que o trabalho plástico não resume a nota do aluno, porque seria uma pequena visão de um todo"; "Não gosto de utilizar as palavras bom aluno e mau aluno, porque qua- lifica muito as pessoas como positivo ou negativo. Dentro da visão qualitativa, busco mais os que estão mais adiante, buscando maiores possibilidades, mais próximos da proposta [...]". Pode-se aqui citar que já em 1994, Penna Firme (1994, p. 6, grifo do autor) dizia: "O momento é mais para inovar em avaliação do que reproduzir tradicionais modelos [...]. É nessa perspectiva que se faz necessário, entre os estudiosos e interessados da avaliação, o exercício pleno da capacidade crítica, porque tendências, que são avanços, e tendenciosidades, que são retrocessos, convivem na teoria e, sobretudo na prática. Distinguir umas e outras é imprescindível".

Considera-se que esta pesquisa possibilite ao docente de Artes Plásticas, através do estudo do pensamento do docente compreender mais o processo educativo e o processo de avaliação do aluno em Artes Plásticas, questionar seus próprios conhecimentos e construir novos conhecimentos, tornando mais coerente o processo de ensino-aprendizagem e o processo de avaliação escolar. Ao mesmo tempo, pretende ajudar o professor de Artes Plásticas a transferir de um sistema privado e implicitamente mantido a uma descrição explícita de seu esquema de referência cognitivo, tornando explícitos e visíveis seus pensamentos, facilitando melhor compreensão de seus pensamentos, teorizações, ações e suas relações. Outra pretensão é que a transformação da concepção que o professor tem de sua função profissional e de avaliador do processo de aprendizagem possa ser desde uma perspectiva de discussão, de diálogo e de compreensão.

Recebido em: 13/04/2004.

Aceito para publicação: 20/05/2004. 


\section{ABSTRACT}

\section{Teachers theories on art evaluation}

The major goal of this text is to present a study on "Teachers Theories on Art Evaluation in order to fathom how an art professor appraises his $5^{\text {th }}$ primary school students and his concernments on evaluation. This study was based on a qualitative focus exploratory nonexperimental pattern. Through interviewing teachers, it was possible to know how an art teacher could understand and theorize on arts valuation. The main purpose was to challenge an unknown area which has been seldom reviewed and examined: Psychology, Arts and Didactic, in order to connect the convergence point among psychologic, artistic and didactic. Public schools from Rio de Janeiro were chosen to be worked out. According to the declarations in this research, it were possible to reach some conclusions: the evidences report that valuing in Arts consists attributing a value's judgment to an reality; through this process a reflexive action is action is sought, "valuing" according to the diagnostic and formative valuation proposal, the teachers Knowledge is to be considered a laic understanding and also as personal pedagogic theories (implicits theories) - those not often perceived - however they are really important for organization the professor's knowledge.

Keywords: Teachers reflections. Art valuation. Implicits theories. Comprehend. Value's judgement. Reflexive action. Laic Knowledge. Psychology. Arts. Didactic.

\section{Resumen}

\section{Teorizaciones de los docentes sobre la evaluación en artes plásticas}

El propósito de este texto es el de presentar en síntesis la investigación "Teorizaciones de los docentes sobre la evaluación en Artes Plásticas", que busca indagar y comprender el pensamiento del docente de Artes Plásticas en la evaluación de los alumnos del segundo ciclo de la enseñanza básica ( $5^{a}$ série do Ensino Fundamental no Brasil). Este estudio se enmarca en un enfoque cualitativo con un diseño no experimental de tipo exploratorio. A través de las entrevistas con los docentes, la declaración del docente considerada "una acción mediada por la palabra", se han buscado las teorías implícitas a fin de convertir en explícitos los marcos de referencia del docente de Artes Plásticas y comprender como él percibe, piensa, teoriza y comprende sobre la evaluación en Artes Plásticas. El interés del investigador ha sido desafiar un campo poco revisado, que es el campo de la Psicología, del Arte y de la Didáctica, buscando el punto donde se interceptan lo psicológico, lo didáctico y lo artístico. El lugar de trabajo ha sido las escuelas públicas municipales de Rio de Janeiro. De las declaraciones obtenidas en esta investigación se llega a determinados resultados: los datos traen evidencias de que en la escuela la actividad de evaluar en Artes Plásticas consiste en la atribución de un juicio de valor a una realidad observada; en el proceso de evaluación en Artes Plásticas se busca una acción más reflexiva, "el 
evaluar" dentro de la propuesta de la evaluación diagnóstica y formativa; el conocimiento del profesor puede ser considerado un conocimiento lego, y también teorías pedagógicas personales (teorías implícitas), éstas no siempre percibidas por los profesores, sin embargo, juegan un papel importante en la organización del conocimiento del docente.

Palabras-clave: Pensamiento del docente. Evaluación en Artes. Teorías implícitas. Comprender. Juicio de valor. Acción reflexiva. Conocimiento lego. Sicología. Arte. Didáctica.

\section{Referências bibliográficas}

BARBOSA, A. M. Arte-educação: leitura no subsolo. São Paulo: Cortez, 2001 a.

A imagem no ensino da arte. São Paulo: Perspectiva, 1996.

. John Dewey e o ensino da arte no Brasil. São Paulo: Cortez, 2001 b.

Tópicos utópicos. Belo Horizonte, MG: Ed. C/Arte, 2000.

BERTONI, A.; POGGI, M.; TEOBALDO, M. Evaluación nuevos significados para una práctica compleja. Buenos Aires: Kapelusz, 1999.

BRUNER, J. S. Actos de significado: más allá de la revolución cognitiva. Traducción de Juan Carlos Goméz Crespo y José Luis Linasa. Madrid: Alianza Editorial, 1991. (Alianza psicología. Psicología Minor; 1).

D'ANCONA, M. A. C. Metodologia cuantitativa: estratégias y técnicas de investigación social. Madrid: Editorial Síntesis, 1998.

DE LA CRUZ, M. Las concepciones sobre la enseñanza en profesorados de nivel medio: profesores y alumnos. 1999. Dissertação (Mestrado em Psicologia da Aprendizagem)Universidad Nacional de Comahue, Argentina, 1999.

DEWEY, J., El arte como experiencia. México, DF: Fondo de Cultura Economica, 1949.

A arte como experiência. São Paulo: Abril Cultural, 1980. (Os pensadores).

. Como pensamos: nueva exposición de la relación entre pensamiento reflexivo y proceso educativo. Barcelona: Editorial Paidós, 1998.

DUARTE JÚNIOR, J. F. Fundamentos estéticos da educação. Campinas, SP: Papirus, 1995. EISNER, E.W. Educar la visión artística. Buenos Aires: Paidós, 1995.

. El ojo ilustrado. Buenos Aires: Paidós, 1998.

ELICHIRY, N. E. Evaluación: Saberes y prácticas docentes. In: SANTOS GUERRA, M. A.; BOGGINO, N. A.; AVENDANO, F. La escuela por dentro y el aprendizaje escolar. Rosario, AR: Homo Sapiens, 2000. 
Evaluación, fracaso escolar y modelos pedagógicos. In: $\overline{\text { niños y }}$ maestros. Buenos Aires: Manantial, 2000. Aprendizaje de

FELDMAN, D. Ayudar a enseñar. Buenos Aires: Aique, 1999. 1995.

. Teorias personales, repertorios sociales. Revista IICE, Buenos Aires, año 95, n. 6,

GARDNER, H. Arte, mente y cerebro: una aproximación cognitiva a la creatividad. Traducción de Gloria G. M. de Vitale. Barcelona: Paidós, 1993.

GIMENO SACRISTÁN, J. Comprender y transformar la enseñanza. Madrid: Morata, 1992.

MONROY, M. Evaluación de la práctica educativa a través de la reflexión del pensamiento didáctico del docente. In: RUEDA BELTRÁN, M.; DÍAZ BARRIGA, F. Evaluación de la docencia: perspectivas actuales. México, Paidós, 2000. cap. 12.

OSTROWER, F. Criatividade e processos de criação. Petrópolis: Editora Vozes, 1983.

- Sensibilidade do intelecto. Rio de Janeiro: Campus, 1998.

. Universos da arte. Rio de Janeiro: Campus, 1991.

PENNA FIRME, T. Avaliação: tendências e tendenciosidades. Ensaio: revista da Fundação Cesgranrio. Rio de Janeiro, v.1, n.2, jan./mar. 1994.

PERRENOUD, P. La construcción del éxito y del fracaso escolar. Madrid: Morata, 1996.

Avaliação: entre duas lógicas: da excelência à regulação das aprendizagens. Tradução Patrícia Chittoni Ramos. Porto Alegre: Artes Médicas, 1999.

POZO, J. Aprender y enseñar. Madrid: Morata, 1998. cap. 4-5.

Aprendices y maestros. Madrid: Alianza Editorial, 1999. cap. 1, 2, 3, 4 (Alianza

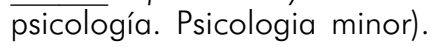

. Teorias cognitivas del aprendizaje. Madrid: Morata, 1989.

RODRIGO, M. J.; RODRÍGUEZ PÉRES, A.; MARRERO, J. Las teorias implícitas: una aproximación al conocimiento cotidiano. Madrid: Visor, [1993]. (Aprendizaje; v. 93).

TORRES, R. M.; BERTONI, A.; CELMAN, S. La evaluación. Buenos Aires: Centro de Publicaciones Educativas y Material Didáctico, 2000. (Novedades educativas).

\section{Correspondência}

suzanaortiz@terra.com.br 